\title{
Kirgiz Chinese
}

National Cancer Institute

\section{Source}

National Cancer Institute. Kirgiz Chinese. NCI Thesaurus. Code C158189.

A Chinese person from the Kirgiz ethnic group. 